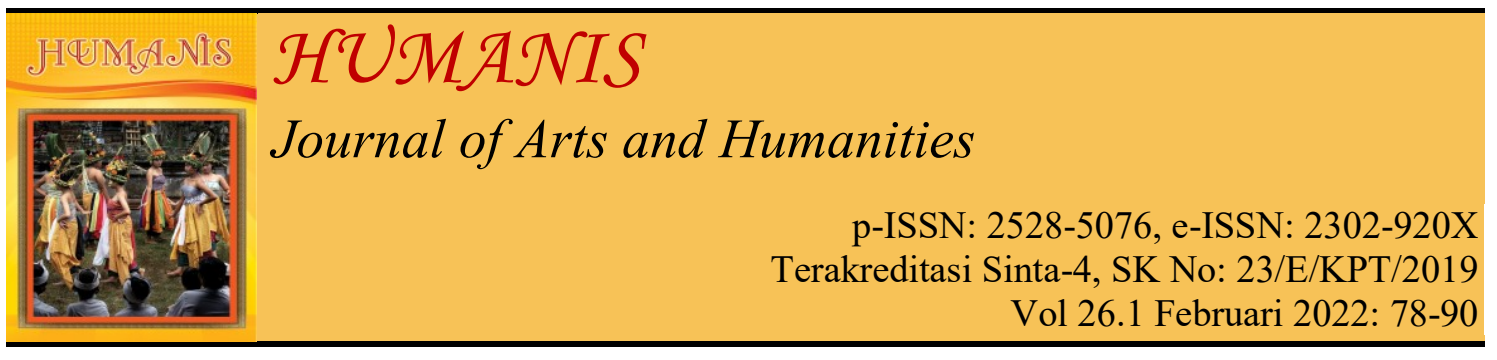

\title{
Pemulihan Trauma Pasca Bencana pada Tokoh Anak dalam Buku Cerita Bergambar (E Hon)
}

\author{
En Nahl Al Atiqo Sanabila Irfana, Silvia Damayanti, Ni Luh Putu Ari Sulatri \\ Universitas Udayana, Denpasar, Bali \\ Email korespondensi: ennahl.alatiqo@gmail.com, silvia_damayanti@unud.ac.id , \\ arisulatri@,unud.ac.id
}

\begin{tabular}{|c|c|}
\hline Info Artikel & Abstract \\
\hline $\begin{array}{l}\text { Masuk: } 17 \text { Desember } 2021 \\
\text { Revisi: } 11 \text { Januari } 2022 \\
\text { Diterima: } 1 \text { Februari } 2022 \\
\text { Keywords: trauma recovery, e } \\
\text { hon, children, Tōhoku Tsunami, } \\
\text { protective factors. }\end{array}$ & $\begin{array}{l}\text { This study aimed to know the form of trauma recovery for child } \\
\text { survivors after the } 2011 \text { Töhoku Tsunami, in the picture book (e } \\
\text { hon) entitled Minna de Utau be! by Mari Mitsuoka. The method } \\
\text { used in this research is descriptive analysis. Theories used in } \\
\text { this research are Sigmund Freud's theory of Literature } \\
\text { Psychology and Resilience theory by Masten (2014). The } \\
\text { analysis results showed that child characters in e hon he her } \\
\text { are described as having characteristics of mild trauma that can } \\
\text { recover quickly through appropriate trauma recovery support. } \\
\text { Those types of recovery support were affected by protective } \\
\text { factors that interconnect and complement each other, such as } \\
\text { the characteristics of child survivors, family support, and } \\
\text { psychological support activities in the school and community } \\
\text { environment. The effectiveness of appropriate recovery aid } \\
\text { enhances children's resilience in the trauma recovery process, } \\
\text { so they can recover and thrive after experiencing a natural } \\
\text { disaster. }\end{array}$ \\
\hline & Abstrak \\
\hline $\begin{array}{l}\text { Corresponding Author: } \\
\text { En Nahl Al Atiqo Sanabila } \\
\text { Irfana } \\
\text { Email: } \\
\text { ennahl.alatiqo@gmail.com }\end{array}$ & $\begin{array}{l}\text { Penelitian ini bertujuan untuk mengetahui bentuk pemulihan } \\
\text { trauma pada tokoh penyintas anak pasca bencana Tsunami } \\
\text { Tōhoku } 2011 \text { dalam e hon Minna de Utau be! karya Mari } \\
\text { Mitsuoka. Metode yang digunakan dalam penelitian ini adalah } \\
\text { metode deskriptif analisis. Analisis dalam penelitian ini } \\
\text { menggunakan teori Psikologi Sastra oleh Sigmund Freud dan } \\
\text { teori Resiliensi oleh Masten (2014). Hasil penelitian } \\
\text { menunjukkan bahwa tokoh penyintas anak dalam e hon } \\
\text { digambarkan memiliki karakteristik trauma ringan yang dapat } \\
\text { pulih dengan relatif cepat melalui dukungan pemulihan trauma }\end{array}$ \\
\hline $\begin{array}{l}\text { DOI: } \\
\text { https://doi.org/10.24843/JH.20 } \\
\text { 22.v26.i01.p09 }\end{array}$ & $\begin{array}{l}\text { yang tepat. Bentuk dukungan pemulihan tersebut dipengaruhi } \\
\text { oleh faktor protektif yang saling berhubungan dan melengkapi } \\
\text { satu sama lain, yaitu karakteristik tokoh anak, dukungan } \\
\text { keluarga, serta dukungan dalam lingkungan sekolah dan } \\
\text { masyarakat. Efektivitas dukungan yang tepat dalam proses } \\
\text { pemulihan trauma telah meningkatkan resiliensi tokoh anak } \\
\text { sehingga mereka dapat pulih dan berkembang pasca } \\
\text { mengalami bencana alam. }\end{array}$ \\
\hline
\end{tabular}




\section{PENDAHULUAN}

Bencana alam menjadi salah satu peristiwa traumatis yang memberikan dampak negatif pada seluruh aspek kehidupan para penyintas anak baik pada aspek fisik, kondisi sosial, maupun psikologis. Sebagai pihak yang paling rentan mengalami paparan risiko bencana, anak-anak memerlukan penanganan khusus dalam proses pemulihan trauma yang berbeda dari penyintas dewasa.

Pasca bencana, beberapa orang tua atau orang dewasa lainnya mempersepsikan anak sebagai pihak yang tangguh sehingga mereka mengabaikan dosis paparan dan respons trauma pada anak-anak. Di sisi lain, para penyintas anak juga dapat berusaha untuk tidak menunjukkan karakteristik trauma mereka pada orang lain (Masten 2014, h.124). Sementara itu, Boyden dan Mann (2005) menjelaskan tentang adanya pemikiran bahwa orang dewasalah yang paling bertanggung jawab untuk memimpin seluruh tindakan pemulihan trauma. Hal ini membuat mereka meragukan strategi alami anak untuk memulihkan dirinya sendiri serta kemampuan untuk mendukung pemulihan orang-orang di sekitar mereka sehingga memunculkan stereotip bahwa anak merupakan pihak penerima intervensi yang pasif dan lemah.

Kesalahan persepsi orang dewasa terhadap kondisi penyintas anak, pada akhirnya akan semakin menghambat proses pemulihan, karena anak-anak tidak menerima bentuk dukungan yang sesuai dengan kebutuhan mereka. Untuk mendukung dan melindungi anak dalam situasi sulit pasca bencana, diperlukan perspektif bahwa anak-anak tidak hanya membutuhkan perlindungan khusus tetapi mereka juga memiliki kemampuan untuk berpartisipasi secara aktif dalam proses pemulihan bencana (Boyden \& Mann, 2005). Efektivitas bentuk dukungan dalam proses pemulihan trauma pada penyintas anak dipengaruhi oleh faktor protektif yang dapat mengurangi paparan risiko pasca bencana sehingga mereka mampu beradaptasi dan pulih dari trauma tanpa mengabaikan kemampuan resiliensi yang dimilikinya.

Kukihara et al. (2014) menjelaskan bahwa dalam peristiwa gempa bumi dan tsunami Tōhoku 2011, resiliensi menjadi salah satu faktor pelindung atau protektif yang berperan baik dalam membantu para penyintas anak untuk memulihkan kembali kondisi gangguan kejiwaan pasca bencana terjadi. Dengan kemampuan tersebut, para penyintas anak tidak hanya mampu menerima dukungan dan bantuan dari orang yang lebih dewasa, tetapi juga turut berpartisipasi dalam proses pemulihan trauma pada penyintas lain. Kondisi ini tercermin dalam karya sastra anak Jepang berupa buku cerita bergambar atau $e$ hon bertemakan kebencanaan.

$E$ hon merupakan sebuah karya sastra anak yang menghubungkan antara dunia imajinasi dan dunia simbolik untuk mewakili keadaan yang terjadi di dunia nyata (Kenichiro, 2012). Pasca bencana Tsunami Tōhoku Maret 2011, ditemukan berbagai bentuk $e$ hon bertemakan pendidikan kebencanaan yang berisi pengetahuan mengenai hal-hal yang harus dilakukan oleh anak-anak dalam menghadapi bencana alam. Beberapa diantaranya merupakan kisah nyata yang ditulis berdasarkan hasil wawancana bersama dengan para penyintas anak di sekitar daerah yang terdampak bencana.

E hon bertemakan 3.11 Ano $\mathrm{Hi}$ no Koto yang berjudul Minna de Utau be! karya Mari Mitsuoka, merupakan e hon yang menceritakan kisah nyata dari perjuangan para tokoh penyintas anak dalam menghadapi dampak negatif akibat peristiwa gempa bumi dan tsunami Tōhoku di Kota Minamisanriku, Prefektur Miyagi. Bacaan yang menggunakan tema bencana cenderung akan memberikan kesan menakutkan bagi anak-anak. Namun, pada $e$ hon yang merupakan karya sastra anak, para penulis cenderung menyampaikan cerita 
bencana dengan menggunakan gaya bahasa yang sesuai sehingga pesan kebencanaan dapat tersampaikan dengan lebih menarik dan tidak menakuti anakanak (Damayanti, 2021). Oleh karena itu, kondisi trauma dan dampak bencana dalam e hon Minna de Utau be! diceritakan secara ringkas dan tidak berlebihan sehingga tidak menimbulkan beban psikologis bagi pembaca anak.

Tokoh anak digambarkan dapat pulih dan berkembang menjadi individu yang resilien atau tangguh dalam menghadapi segala dampak negatif pascabencana. Hal ini juga dilakukan untuk memberikan dukungan pada para penyintas anak melalui pesan-pesan semangat yang tercermin dalam cerita $e$ hon.

Berdasarkan uraian di atas, bagaimana bentuk-bentuk pemulihan trauma yang tepat pasca bencana gempa bumi dan tsunami bagi tokoh penyintas anak dalam e hon menjadi pokok masalah yang dibahas dalam penelitian ini. Penelitian mengenai bencana alam dalam buku cerita bergambar (e hon) sebelumnya pernah dilakukan oleh Damayanti et al. (2020) dengan judul "Disaster Discourse in Children's Story Books". Penelitian Damayanti et al. memberikan gambaran mengenai wacana gempa bumi dan tsunami Tōhoku dalam karya sastra anak berbentuk e hon. Selain itu, penelitian ini juga menggunakan penelitian berjudul "Dampak Psikologis Tokoh Pria dan Wanita dalam Film Tangshan Da Dizhen" oleh Sinarsih et al. (2015). Penelitian Sinarsih et al. memberikan gambaran mengenai kondisi trauma pasca bencana serta faktor-faktor yang mempengaruhi pemulihan trauma pada tokoh penyintas anak.

Secara khusus, penelitian ini bertujuan untuk mengetahui bentuk pemulihan trauma melalui faktor-faktor protektif yang mendukung proses pemulihan tokoh penyintas anak pasca bencana gempa bumi dan tsunami dalam e hon Minna de Utau be! karya Mari Mitsuoka.

\section{METODE DAN TEORI}

Penelitian ini menggunakan sumber data berupa cerita bergambar berjudul Minna de Utau be! karya dari penulis Mari Mitsuoka dan ilustrator Yoshiko Okamoto yang termuat dalam e hon Kataritsugi Ohanashi Ehon San gatsu Jyuu Ichi Nichi: Kodomotachi no Chikara volume lima dan diterbitkan oleh Gakken education publishing pada tahun 2013. Prosedur pengumpulan data dalam penelitian ini dilakukan dengan metode studi kepustakaan melalui teknik simak baca dan catat. Data dalam bahasa Jepang kemudian diterjemahkan ke dalam bahasa sasaran dengan menggunakan metode penerjemahan bebas yang lebih mengutamakan isi dan maksud dari suatu kalimat melalui parafrase dari suatu informasi yang implisit dalam bahasa Jepang. Selanjutnya data yang telah diterjemahkan tersebut dianalisis dengan metode deskriptif analisis dan disajikan dalam bentuk informal.

Penelitian ini menggunakan dua teori, yaitu teori Psikologi Sastra oleh Sigmund Freud dan teori Resiliensi oleh Masten (2014). Menurut Aras (2015), meskipun psikologi dan sastra merupakan dua bidang ilmu yang berbeda, tetapi keduanya memiliki korelasi yang kuat dalam menganalisis seluruh aspek kehidupan manusia seperti perilaku, sifat, keberadaan dan lainnya melalui berbagai konsep, metode, dan pendekatan. Psikologi sastra merupakan salah satu dari telaah sastra yang menggambarkan unsur-unsur psikologis sebagai manifestasi proses serta aktivitas psikis pengarang, para tokoh dalam cerita, serta pembaca karya sastra (Minderop 2018, h.53 - 54). Dalam penelitian ini, Psikologi Sastra oleh Sigmund Freud digunakan untuk memahami karakteristik trauma maupun kemampuan internal tokoh penyintas anak dalam menghadapi peristiwa bencana

Selain teori tersebut, teori Resiliensi dari Masten (2014) juga digunakan 
untuk menemukan bentuk pemulihan trauma yang sesuai dengan konsep resiliensi. Penggunaan kerangka resiliensi memberikan pandangan dinamis tentang interaksi antara seseorang dan lingkungannya yang terbagi ke dalam faktor internal dan eksternal. Masten (2014, h.154-165) menjelaskan bahwa faktor protektif internal dapat dilihat dari karakteristik yang terdapat dalam diri individu, seperti intelegensi, kemampuan dalam memecahkan masalah, regulasi dan pengarahan diri, efikasi diri, kepercayaan dan keyakinan bahwa hidup memiliki arti, serta kepribadian anak yang memiliki pandangan hidup positif. Dalam faktor protektif eksternal, resiliensi pada individu dapat dipengaruhi oleh interaksi dan hubungan mereka dengan lingkungan keluarga, teman, sekolah, masyarakat, dan budaya (ibid, h.171). Dengan kedua teori tersebut, penelitian ini menganalisis bentuk pemulihan trauma pada tokoh penyintas anak berdasarkan faktor protektif yang mendukung proses pemulihan trauma yaitu faktor internal berupa karakteristik anak serta faktor eksternal berupa dukungan dari lingkungan keluarga, sekolah, dan masyarakat dalam e hon Minna de Utau be! karya dari penulis Mari Mitsuoka.

\section{HASIL DAN PEMBAHASAN}

Minna de Utau be! merupakan e hon yang berpusat pada pola kehidupan tokoh penyintas anak Sekolah Dasar Togura bernama Kumagai Misato dalam konsep resiliensi yang ditandai dengan kondisi trauma dan dan pemulihannya saat menghadapi bencana tsunami Tōhoku 2011. Misato yang pada awalnya digambarkan sebagai tokoh yang aktif dan ceria, menunjukkan beberapa karakteristik trauma tepat setelah mengalami peristiwa tsunami Tōhoku. Karakteristik tersebut ditunjukkan melalui beberapa respons, yaitu perasaan takut terhadap bencana dan keselamatan dirinya sendiri, kecemasan terhadap kondisi orang-orang terdekatnya, dan respons kilas balik atau flashback yang disertai dengan gangguan pada fisik berupa peningkatan detak jantung dan sakit pada dada. Selain Misato, tokoh Shiori yang merupakan teman dekat Misato serta salah satu anak dalam usia prasekolah juga menunjukkan respons trauma berupa ketakutan terhadap bencana dan kecemasan akan keselamatan dirinya.

Meskipun demikian, para tokoh penyintas anak tersebut dapat menjadi individu resilien yang dapat pulih dari trauma melalui kombinasi antara bentuk dukungan yang tepat dari lingkungan luar dan kapasitas alami anak untuk memulihkan diri. Penelitian ini membahas bentuk dukungan pemulihan pada tokoh penyintas anak sesuai dengan pandangan resiliensi yang dipengaruhi oleh tiga faktor protektif berupa karakteristik individu, dukungan keluarga, serta dukungan dalam lingkungan sekolah dan komunitas. Adapun hasil penelitian tersebut dijabarkan sebagai berikut.

\section{Faktor Karakteristik Individu}

Faktor individu mengacu pada kapasitas internal yang mendukung dan mempengaruhi kemampuan tokoh penyintas anak dalam menanggapi risiko dari pengalaman traumatis bencana. Pada e hon Minna de Utau be!, karakteristik individu tidak hanya ditemukan dalam diri tokoh Misato, tetapi juga pada tokoh penyintas lain yang berada dalam kelompok usia sekolah. Karaktristik tersebut berupa regulasi diri dan pengendalian impuls, empati, serta keterikatan dalam hubungan dekat anak.

Regulasi diri merupakan kemampuan anak untuk mengendalikan diri dari perhatian, gairah, emosi, serta impuls atau dorongan untuk melakukan suatu perbuatan (Masten, 2014). Meskipun tokoh Misato digambarkan sebagai penyintas anak yang menunjukkan karakteristik trauma, di sisi lain ia juga 
memiliki kemampuan regulasi diri dan pengendalian impuls yang baik. Hal ini ditunjukkan pada data (1).

(1) 5，6 年生と先生、地域の人たちは、 野宿だ。

社の中に入りたかったけど、これ 以上入ったら、つぶれてしまうか

もしれない。がまんしなくちや。

Go, roku nensei to sensei, chiiki no hito tachi wa, nojuku da.

Yashiro no naka ni hairitakatta kedo, kore ijo haittara, tsuburete shimau kamo shirenai. Gaman shinakucha.

Terjemahan:

Siswa kelas lima, enam, para guru dan juga penduduk desa bermalam di luar kuil.

Sebenarnya Misato ingin masuk ke dalam kuil, tetapi kalau dia masuk ke sana mungkin kuil itu akan runtuh. Misato harus bertahan.

(Minna de Utau be! Vol 5, 2013: 36 - 37)

Data (1) merupakan narasi yang menunjukkan upaya Misato dalam mengendalikan impuls yang muncul pada dirinya. Pada saat proses evakuasi bencana, sebagai pihak yang lebih rentan, hanya anak yang lebih muda dan lansia saja yang menjadi prioritas untuk masuk ke dalam Kuil Isuzu. Kondisi bangunan yang sangat tua dan rapuh tidak memiliki kapasitas yang besar untuk menampung semua penyintas anak didalamnya. Oleh karena itu, Misato harus merelakan dirinya untuk bermalam di halaman Kuil Isuzu bersama dengan para penyintas yang lebih dewasa lainnya.

Pada awalnya, rendahnya suhu udara di luar kuil mengaktifkan aspek id yang mendorong Misato memiliki keinginan untuk mencari kehangatan dan perlindungan dengan masuk ke dalam kuil. Namun, kehadiran ego dan superego yang lebih dominan menyadarkan Misato bahwa keinginannya tersebut tidak dapat direalisasikan. Kemampuan regulasi diri yang baik, membuat Misato berupaya untuk meredam tuntutan $i d$ dengan tetap bertahan di tengah dinginnya udara di luar kuil.

Dengan perkembangan kognitif dan kesadaran moral yang lebih baik, Misato memahami bahwa kemungkinan besar kuil tersebut akan runtuh apabila ia memaksakan diri untuk masuk ke dalam sana. Hal ini hanya akan mengganggu keamanan dan kenyamanan para penyintas lainnya. Oleh karena itu, meskipun terdapat keinginan besar dalam dirinya untuk masuk ke dalam kuil, ia tetap menahan diri dari tindakan impulsif yang dapat merugikan orang lain.

Keberhasilan Misato dalam mengendalikan impuls juga dapat dilihat saat ia menerima bantuan selimut dan makanan dari penduduk di sekitar Kuil Isuzu. Misato menunjukkan kemampuannya dalam menahan dan membatasi diri untuk tidak berlaku egois saat menerima bantuan tersebut. Hal ini dapat dilihat pada gambar (1).

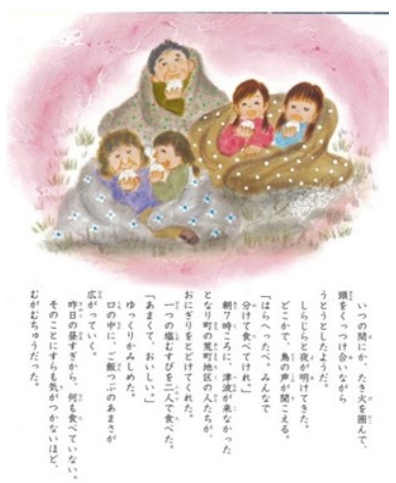

Gambar (1) Misato dan Shiori berbagi makanan dan selimut

(Minna de Utau be! Vol 5, 2013: 40)

Gambar (1) menggambarkan keadaan tokoh Misato yang sedang berbagi selimut dengan Shiori sembari menikmati shio musubi. Shio musubi merupakan salah satu jenis onigiri asin yang tidak memiliki isian apapun dan tidak dibungkus oleh rumput laut. Pada malam hari saat air tsunami telah surut, Misato dan para penyintas yang berada di 
luar kuil mendapatkan bantuan selimut dari para penduduk bukit. Misato yang sebelumnya telah berhasil menahan diri untuk tidak masuk ke dalam kuil, harus kembali mengendalikan dirinya untuk tidak egois dan tetap berlaku sesuai dengan nilai-nilai moral. Meskipun merasa kedinginan, Misato secara sukarela menggunakan satu selimut yang sama dengan Shiori agar sahabatnya itu tidak merasa kedinginan.

Levine dan Kline (2010, h.79-80) menjelaskan bahwa anak-anak dalam usia sekolah telah memiliki banyak tuntutan dan tanggung jawab yang dibebankan untuk berkonsentrasi dan belajar sehingga mereka memiliki lebih banyak sumber daya, seperti bahasa yang lebih berkembang, serta kemampuan kognitif dan kesadaran moral yang lebih baik. Dengan kemampuan tersebut, tokoh Misato dapat memahami tindakan baik dan buruk yang harus dilakukan saat menghadapi peristiwa yang penuh dengan tekanan. Regulasi diri membuat anak berupaya untuk mengendalikan dirinya dan berperilaku sesuai dengan moral yang berlaku lingkungannya.

Faktor protektif individu lainnya yang ditunjukkan oleh tokoh penyintas anak dalam e hon Minna de Utau be! berupa kesediaan untuk peduli pada orang lain dan kemampuan untuk berempati terhadap kebutuhan orang lain. Sebagai anak yang berada dalam kelompok usia anak paling dewasa, tokoh Misato, Minaho, dan siswa kelas enam memiliki rasa empati yang tinggi terhadap anak-anak yang lebih muda dan juga lansia. Mereka turut berkontribusi dalam memberikan bantuan pada pihak yang lebih rentan saat proses evakuasi berlangsung. Hal ini tercermin dalam perilaku tokoh penyintas anak yang ditunjukkan pada data (2).

\section{(2) 先生たちが、無人の社の安全を確} 認した後、1 年生から 4 年生まで
と、保育園児をふくむ 90 人ほど の子どもたちを、順番にゆうどう することになった。保育園児が泣 きだした。

$$
\text { 「だいじょうぶだよ。」みなほが、 }
$$
女の子の手を引いて、中へ連れて いつた。

「こちらへどうぞ。」みさとたち

6 年生は、お年よりたちの手を引

いて、社にゆうどうした。

Sensei-tachi ga, mujin no yashiro no anzen o kakuninshita ato, ichi-nensei kara yon-nensei made to, hoikuenji o fukumu kyüjyū nin hodo no kodomotachi o, junban ni yūdōsuru koto ni natta. Hoikuenji ga naki dashita.

"Daijōbu da yo.", Minaho ga, onna no ko no te o hiite, naka e tsurete itta.

"Kochira e dōzo.", Misato tachi roku nensei wa, otoshi yori tachi no te o hiite, yashiro ni yūdō shita.

Terjemahan:

Setelah para sensei memastikan keamanan kuil yang tidak berpenghuni tersebut, sekitar 90 anak mulai dari kelas satu hingga kelas empat, termasuk juga anak-anak prasekolah, diarahkan secara bergiliran menuju ke dalam kuil. Anak prasekolah itu pun mulai menangis.

"Tenang, semua akan baik-baik saja.", Minaho memegang tangan anak perempuan itu dan membawanya masuk ke dalam kuil.

Misato dan anak kelas enam lainnya memegang tangan para lansia dan mengantarkan mereka masuk ke dalam kuil.

(Minna de Utau be! Vol 5, 2013: 36)

Data (2) menunjukkan keterlibatan para tokoh penyintas anak dalam proses 
evakuasi. Tokoh Misato dan siswa kelas enam lainnya digambarkan sedang mengarahkan para lansia sembari memegang tangan mereka dan membantu mereka berjalan hingga ke dalam kuil. Lain halnya dengan tokoh Minaho, ia dengan sigap mencoba menenangkan salah satu tokoh anak prasekolah yang mulai menangis. Menurut Reivich dan Shatte (2003, h.50-52), empati menentukan bagaimana individu mampu membaca tanda-tanda kondisi emosional dan psikologis orang lain.

Dengan kemampuan tersebut, Minaho dapat memahami bahwa respons menangis yang ditunjukkan oleh anak prasekolah tersebut merupakan tanda bahwa ia sedang merasa ketakutan dengan situasi bencana tsunami. Oleh karena itu, Minaho berusaha memberikan dukungan yang menenangkan pada anak tersebut. Selain itu, kemampuan empati juga akan membantu anak untuk memiliki hubungan sosial positif yang ditandai dengan munculnya perilaku prososial yang memungkinkan mereka untuk saling berbagi pengalaman dan kebutuhan satu sama lain (Reiss dalam Suparmi \& Sumijati, 2021).

Masten (2014, h.126) menjelaskan bahwa dalam situasi bencana, anak-anak yang lebih dewasa akan terus terlibat untuk membantu pihak yang lebih rentan dari dirinya. Hal ini sejalan dengan rasa empati dan perilaku altruisme yang ditunjukkan oleh Misato, Minaho, dan tokoh siswa kelas enam lainnya untuk turut membantu penyintas anak prasekolah dan para lansia mendapatkan perlindungan lebih awal dibandingkan dengan diri mereka sendiri.

\section{Faktor Keluarga}

Keluarga terutama orang tua merupakan figur kelekatan yang paling dekat dan memiliki pengaruh paling besar dalam proses pemulihan trauma pada anak. Salah satu tindakan efektif yang dapat dilakukan oleh orang tua adalah membangun kembali keamanan dan rutinitas anak dengan menyediakan ruang yang mendukung anak untuk melakukan aktivitas secara normal (Hafstad et al., 2012). Pemulihan rutinitas kehidupan anak ini tercermin dalam tindakan yang dilakukan oleh tokoh ibu Misato pada e hon Minna de Utau be!. Ibu Misato digambarkan bekerja sama dengan ibu-ibu lain di pengungsian dalam mencari bantuan untuk mewujudkan keinginan anak-anaknya. Hal ini ditunjukkan pada data (3).

（3）「制服が全員分、そろつたよ!」

みさとが夏休みの補習から帰つて くると、お母さんが、笑顔で出迎 えてくれた。

「え?ほんと！じやあ、卒業式が できるんだね!」

お母さんたちや制服業者の方の協 カで、戸倉中学校の制服が卒業生 全員におくられることになり、戸 倉小学校の卒業式がとり行われる ことになったのだ。転校していつ た仲間の分もちゃんとそろえられ た。

"Seifuku ga zeninbun, sorotta yo!" Misato ga natsu yasumi no hoshū kara kaette kuru to, okāsan ga, egao de demukaete kureta.

"E? Honto! Jā, sotsugyōshiki ga dekirunda ne!"

Okāsan tachi ya seifuku gyōsha no kata no kyōryoku de, Togura chūgakkō no seifuku ga sotsugyōsei zenin ni okurareru koto ni nari, Togura shōgakkō no sotsugyōshiki ga toriokonawareru koto ni natta noda. Tenkōshiteitta nakama no bun mo chanto soroerareta.

Terjemahan: 
Saat Misato kembali dari kegiatan pelajaran tambahan liburan musim panasnya, ibunya menyambut Misato dengan senyuman dan berkata, "Kita telah memiliki seragam sekolah untuk semua anak!".

"Hah? Benarkah! Kalau begitu kita bisa mengadakan upacara kelulusan kan!".

Atas kerjasama dari ibu-ibu dan pengusaha seragam sekolah, maka seragam SMP Togura akan dikirimkan kepada semua alumni, dan upacara kelulusan Sekolah Dasar Togura akan diselenggarakan. Seragam untuk temua-teman Misato yang telah pindah sekolah pun juga dipersiapkan dengan baik.'

(Minna de Utau be! Vol 5, 2013: 44)

Data (3) merupakan narasi yang menunjukkan keberhasilan ibu Misato dan para ibu lainnya di pengungsian dalam mewujudkan keinginan anakanaknya untuk mengadakan upacara kelulusan sekolah. Untuk mengembalikan semangat dan kebahagiaan para tokoh penyintas anak yang merasa sedih karena harus memulai kehidupan sekolah menengah pertama mereka tanpa mengadakan upacara kelulusan, ibu Misato dan para ibu di pengungsian mulai bekerja sama dengan pengusaha konveksi seragam dalam upaya pembuatan seragam sekolah baru. Dengan seragam tersebut, Misato dan temannya dapat merealisasikan keinginan mereka untuk mengadakan upacara kelulusan sekolah.

Sebagai pihak yang memulai dukungan tersebut, tokoh ibu Misato telah berhasil menjalin hubungan dan kepercayaan dengan para ibu di pengungsian serta pihak konveksi untuk memulihkan kembali kondisi anak-anak pasca bencana. Hal ini sejalan dengan peran keluarga untuk memulihkan bencana dalam pandangan resiliensi. Masten (2014, h.212) menyebutkan bahwa keluarga tidak hanya menyediakan kebutuhan fisik untuk anak-anak mereka, tetapi juga dapat memberikan kesempatan dan sumber daya sosial. Keluarga juga memiliki peran utama dalam memfasilitasi pendidikan dan kegiatan ekstrakurikuler melalui dukungan finansial dan keterlibatan pihak lain dalam ruang lingkup sosial yang lebih luas.

\section{Faktor Sekolah dan Masyarakat}

Pada e hon Minna de Utau be!, para penyintas dewasa dalam lingkungan sekolah dan masyarakat digambarkan memberikan bentuk dukungan yang bervariasi pada anak, mulai dari pemenuhan kebutuhan dasar anak, dukungan yang menenangkan, dan pembukaan kembali fasilitas sekolah. Bentuk pemulihan tersebut dijabarkan sebagai berikut.

\section{a. Pemenuhan Kebutuhan Dasar}

E hon Minna de Utau be memberikan gambaran mengenai bentuk dukungan yang berfokus pada pemenuhan kebutuhan dasar anak melalui tindakan para penduduk di sekitar Kuil Isuzu. Asogawa (2011) menjelaskan bahwa para penduduk tidak hanya memberikan dukungan berupa selimut dan kasur lipat, tetapi juga membagikan makanan yang didapatkan dari rumahrumah di sekitar bukit kepada para penyintas anak dan penyintas dewasa yang terluka. Peran masyarakat dalam pemulihan bencana menunjukkan bahwa faktor pelindung individu dan keluarga bergantung pada tingkat resiliensi masyarakat.

Masyarakat dapat memberikan dukungan kepada anak dan keluarga melalui pemenuhan kebutuhan praktis sehari-hari seperti makanan, air bersih, keselamatan, fasilitas medis, serta layanan darurat (Masten 2014, h.215). Selain itu, para tokoh penyintas dewasa juga digambarkan memberikan kesempatan pada tokoh penyintas anak untuk turut berpartisipasi dalam 
menciptakan kehangatan melalui api unggun. Hal ini ditunjukkan pada gambar (2).

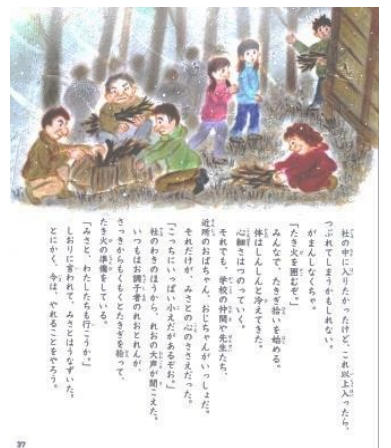

Gambar (2) Para penyintas saling bekerja sama menciptakan api unggun

(Minna de Utau be! Vol 5, 2013: 37)

Gambar (2) menunjukkan bentuk kerjasama antara para tokoh penyintas anak dan penyintas dewasa. Tokoh Misato dan Shiori digambarkan sedang berjalan menuju sisi kuil untuk membantu tokoh Leo yang telah terlebih dahulu mengumpulkan kayu bakar. Para sensei dan penduduk desa juga terlihat saling bekerja sama untuk memberikan kehangatan pada para penyintas dengan menyalakan beberapa api unggun di sekitar kuil. Kondisi para penyintas yang ditunjukkan pada gambar (2) merupakan realita yang dialami oleh para penyintas yang menyelamatkan diri di Kuil Isuzu.

Dalam peristiwa Tōhoku, para penyintas di daerah bencana digambarkan dapat bertahan dalam situasi yang sulit serta berusaha untuk tetap hidup dengan tetap tenang dan saling memberikan dukungan serta semangat satu sama lain (Miyagiken Kodomo Sōgō Sentā, 2016). Mereka saling bekerja sama untuk membuat api unggun agar dapat bertahan hidup di tengah genangan air tsunami dan dinginnya udara malam. Dalam kegiatan tersebut, para tokoh penyintas dewasa tidak memandang penyintas anak sebagai pihak pasif yang hanya menerima bantuan. Tindakan yang dilakukan oleh penyintas dewasa ini sesuai dengan pandangan resiliensi yang melihat anak sebagai pihak yang memiliki kemampuan untuk berpartisipasi secara langsung dalam kebijakan dan tindakan pemulihan bersama dengan orang dewasa lainnya (Boyden \& Mann, 2005).

b. Dukungan yang Menenangkan

Ketika menghadapi bencana, para penyintas anak berada dalam kondisi emosional yang tidak stabil dan penuh dengan kecemasan, seperti halnya yang digambarkan dalam karakter tokoh Misato pada e hon Minna de Utau be!. Untuk meredam kecemasan tersebut, salah satu tokoh penyintas menghibur tokoh Misato dengan cara mengajak semua orang bernyanyi bersama. Nakamura (2017) menjelaskan bahwa musik memiliki kekuatan untuk membantu memulihkan kondisi individu yang mengalami trauma pasca bencana tsunami Tōhoku. Dengan bernyanyi dan mendengarkan musik, pernapasan dan denyut nadi tanpa sadar akan melambat. Hal ini dapat membuat seseorang menjadi lebih tenang. Dengan menghilangkan ketegangan yang dihasilkan oleh risiko bencana, anak-anak dapat melepaskan emosi negatif mereka secara perlahan, sehingga mereka dapat menghadapi situasi bencana dengan pikiran dan tubuh yang tenang.

Selain bernyanyi, salah satu guru yang berperan sebagai wali kelas tokoh Misato, juga memberikan dukungan dengan menciptakan suasana yang menyenangkan bagi anak-anak. Hal ini dapat dilihat pada gambar (3).

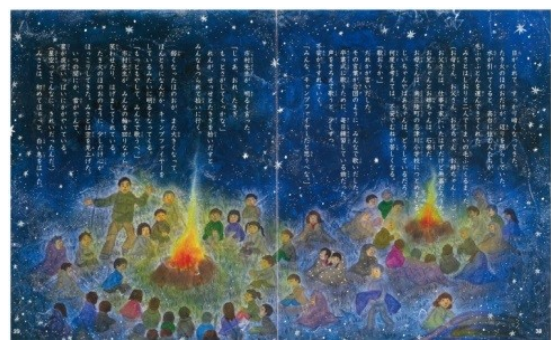

Gambar (3) Para penyintas mengelilingi api unggun (Minna de Utau be! Vol 5, 2013: 38 - 39)

Gambar (3) menunjukkan keadaan para penyintas yang sedang mengelilingi api unggun. Ichimura sensei terlihat 
sedang berdiri di antara para penyintas anak dan dewasa. Dengan ceria, ia mengajak anak-anak untuk membuat kobaran api menjadi lebih besar agar semakin terlihat seperti api unggun perkemahan yang sesungguhnya. Tokoh Ichimura sensei digambarkan dengan bersemangat mengajak anak-anak untuk membayangkan seolah-olah mereka sedang berada dalam kegiatan perkemahan yang menyenangkan. Ia terus berupaya meredam kecemasan dan kekhawatiran anak dengan memberikan mereka kenyamanan serta hiburan.

Sebagai seorang guru, Ichimura sensei memiliki peran dalam mengendalikan emosi anak-anak. Guru tidak hanya berperan dalam memberikan pendidikan kebencanaan pada anak, tetapi juga dalam setiap proses pemulihan trauma setelah terjadinya bencana (Mohammadinia et al., 2018). Di luar lingkungan keluarga, figur guru sering disebut sebagai sumber dukungan di antara anak-anak resilien. Masten menyatakan bahwa seorang guru dapat menjadi panutan dan memberikan keamanan emosional yang muncul melalui keterkaitan hubungan dengan muridnya (2014, h.227-228). Oleh karena itu, Ichimura sensei berusaha untuk terlihat tenang dan ceria agar para murid yang berada disekitarnya juga dapat merasakan hal yang sama. Ia terus mengajak anak-anak untuk bernyanyi dan menghiburnya dengan lelucon yang membuat para penyintas anak tertawa. Sikap dan tindakan yang dilakukan oleh Ichimura sensei ini telah sesuai dengan tanggung jawab seorang guru kepada muridnya saat berada dalam situasi yang sulit, seperti bencana.

\section{c. Pembukaan Fasilitas Sekolah}

Lingkungan sekolah memiliki peran utama dalam pemulihan dari berbagai jenis bencana. Brocque et al. (2017) menjelaskan bahwa sekolah merupakan kunci utama dalam membantu para siswa untuk mendapatkan kembali rasa aman dalam kondisi yang penuh dengan kesulitan pascabencana. Hal ini dikarenakan sekolah telah menjadi simbol pemulihan dan resiliensi bagi anak-anak, orang tua, dan masyarakat yang mengalami bencana alam (Masten 2014, h.238). E hon Minna de Utau be, menunjukkan gambaran dari kehidupan normal pasca bencana yang diawali dengan pembukaan kembali fasilitas sekolah. Hal ini ditunjukkan oleh data (4).

(4) 登米での避難生活が始まった。 卒業式もできないまま、廃校だつ た善王寺小学校を借りて、戸倉小 学校・中学校の新学期が始まった。 Toyoma de no hinan seikatsu ga hajimatta.

Sotsugyōshiki mo dekinai mama, haikō datta Zennōji shōgakkō o karite, Togura shōgakkō, chūgakkō no shingakki ga hajimatta.

Terjemahan:

Kehidupan di tempat pengungsian Toyoma pun telah dimulai. Tanpa mengadakan upacara kelulusan, semester baru SD - SMP Togura telah dimulai dan mereka meminjam bangunan SD Zenouji yang telah ditutup.

(Minna de Utau be! Vol 5, 2013: 38)

Data (3) menunjukkan narasi yang memuat kondisi aktivitas sekolah tokoh penyintas anak di Prefektur Miyagi pasca bencana tsunami. Tokoh Misato dan beberapa penyintas anak yang bersekolah di SD Togura digambarkan telah memulai aktivitas mereka sebagai siswa sekolah menengah pertama dengan menggunakan bangunan Sekolah Dasar Zenouji yang telah ditutup sebagai sekolah baru mereka. Hal ini dikarenakan seluruh bangunan sekolah yang berada di Togura telah tersapu oleh gelombang tsunami. 
Kondisi ini sesuai dengan realita yang terdapat di lingkungan sekolah Prefektur Miyagi pasca bencana tsunami terjadi. Banyak dari penyintas anak dari sekolah yang berbeda harus menggunakan satu bangunan sekolah yang sama. Mereka juga bersekolah tanpa menggunakan perlengkapan sekolah yang lengkap (Miyagiken Kodomo Sōgō Sentā, 2016). Meskipun penuh dengan kekurangan, tokoh Misato dan penyintas anak lainnya digambarkan merasa senang, karena dengan bersekolah, mereka dapat saling berinteraksi kembali dan juga melakukan aktivitas secara normal seperti sebelum terjadi bencana. Hal ini juga didukung oleh gambar (4).

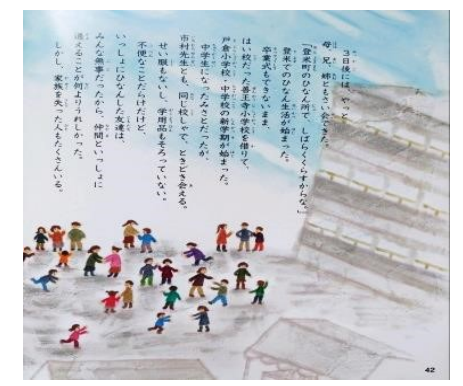

Gambar (11) Para penyintas anak bermain di sekolah (Minna de Utau be! Vol 5, 2013: 43)

Gambar (4) menunjukkan gambaran para penyintas anak yang sedang berinteraksi dan bermain di halaman sekolah. Para penyintas anak menunjukkan keceriaan saat bermain dengan saling membentuk kelompokkelompok bersama para penyintas anak lainnya. Pemberian dukungan melalui pembukaan lingkungan sekolah pasca bencana yang tercermin dalam e hon Minna de Utau be! telah menunjukkan bahwa sekolah juga memiliki peran sentral dalam kesiapsiagaan dan pemulihan bencana. Hal ini dikarenakan sekolah telah menjadi tempat bagi anakanak dalam mengembangkan kemampuan dan memberikan anak-anak harapan di masa depan serta membangun hubungan dengan figur kelekatan lain di luar keluarganya.
Ketika sekolah ditutup untuk waktu yang lama, akan menimbulkan efek mendalam dan meluas tidak hanya pada individu yang terkena dampak langsung, tetapi juga pada seluruh keluarga dan masyarakat. Pendidikan merupakan kunci fundamental dalam membantu mengurangi dampak bencana terhadap seluruh penyintas pascabencana (Baytiyeh, 2019). Oleh karena itu, membangun kembali rutinitas dan fungsi sekolah secara luas dapat memberikan keyakinan dan harapan bagi penyintas anak bahwa mereka masih dapat memiliki masa depan yang cerah meskipun dalam situasi bencana yang penuh dengan kesulitan. Dengan hal ini, para penyintas anak dapat mengembangkan kemampuan mereka untuk pulih dari trauma pasca bencana.

\section{SIMPULAN}

Berdasarkan analisis yang telah dilakukan, dapat disimpulkan bahwa tokoh anak dalam e hon Minna de Utau be! tidak hanya menerima dukungan secara pasif, tetapi juga mendapatkan kesempatan untuk mengembangkan kemampuan resiliensinya dengan berpartisipasi secara langsung dalam tindakan pemulihan trauma pada penyintas lain. Bentuk dukungan pemulihan yang sesuai dengan pandangan resiliensi tersebut dipengaruhi oleh tiga faktor protektif berupa karakteristik individu, dukungan keluarga, serta dukungan dalam lingkungan sekolah dan komunitas.

Tokoh anak yang merupakan siswa Sekolah Dasar Togura, termasuk tokoh utama Misato digambarkan memiliki karakteristik tangguh berupa regulasi diri dan pengendalian impuls, empati, serta keterikatan hubungan dengan orangorang terdekatnya. Selain itu, faktor protektif yang terlibat dalam proses pemulihan juga ditunjukkan melalui hubungan dan interaksi para tokoh dengan sumber daya eksternal. Pada faktor keluarga, bentuk dukungan 
pemulihan tercermin dalam upaya yang dilakukan oleh tokoh ibu Misato saat bekerja sama dengan para ibu lainnya di pengungsian untuk memfasilitasi anakanaknya yang ingin melakukan upacara kelulusan. Para tokoh penyintas anak juga digambarkan mendapatkan dukungan dari para tokoh penyintas dewasa dalam lingkungan sekolah dan masyarakat berupa pemenuhan kebutuhan dasar anak, dukungan yang menenangkan, serta pembukaan kembali fasilitas sekolah.

Melalui pandangan resiliensi, tokoh orang tua dan tokoh dewasa lainnya dapat bekerja sama bersama para penyintas anak dalam memulihkan kondisi trauma dengan memaksimalkan kapasitas alami anak dan juga memberikan dukungan yang sesuai dengan perspektif yang dimiliki oleh anak, sehingga proses pemulihan trauma dapat berlangsung secara efektif dan cepat. Diharapkan penelitian selanjutnya dapat mengkaji pengurangan risiko bencana dalam ruang lingkup komunitas atau masyarakat dengan menggunakan pendekatan sosiologis sehingga didapatkan bentuk pemulihan trauma dan perubahan kehidupan pasca bencana alam melalui perspektif lingkungan sosial yang lebih luas.

\section{DAFTAR PUSTAKA}

Aras, G. (2015). Personality and Individual Differences: Literature in Psychology-Psychology in Literature. Procedia-Social and Behavioral Sciences, 185, 250-257. 10.1016/j.sbspro.2015.03.452.

Asogawa, A. (2011). Higashi Nihon Daishinsai ni okeru Togura Shōgakkō no Hinan ni tsuite - Jidō no Hikiwatashi ga Shūryōsuru made no Hinan ni tsuite. Miyagi Prefectural Government. https://www.pref.miyagi.jp/uploade d/attachment/12404.pdf.
Baytiyeh, H. (2019). Why School Resilience Should Be Critical for the Post-Earthquake Recovery of Communities in Divided Societies. Education and Urban Society, 51(5), 693-711. https://doi.org/10.1177/001312451 7747035 .

Boyden, J. \& Mann, M. (2005). Children's Risk, Resilience, and Coping in Extreme Situations. In Michael Ungar (Eds.), Handbook for Working with Children and Youth: Pathways to Resilience across Cultures and Contexts (pp. 3-26). SAGE Publications. http://dx.doi.org/10.4135/97814129 76312.n1.

Brocque, R., Young, A., Montague, G., Pocock, S., March, S., Triggell, N., Rabaa, C., \& Kenardy, J. (2017). Schools and Natural Disaster Recovery: The Unique and Vital Role That Teachers and Education Professionals Play in Ensuring the Mental Health of Students Following Natural Disasters. Journal of Psychologists and Counsellors in Schools, 27(1), 1-23. doi:10.1017/jgc.2016.17.

Damayanti, S., Suarka, I.N, \& Ari Sulatri, N.L. (Eds.). (2020). Disaster Discourse in Children's Story Books. Proceedings of the 1 st International Conference on Folklore, Language, Education and Exhibition (ICOFLEX 2019). Atlantis Press. https://doi.org/10.2991/assehr.k.20 1230.038 .

Damayanti, S. (2021). Penerapan Analisis AWK van Djik: Pendidikan Kebencanaan dalam Wacana Naratif Daijiishin Kara no Onegai Karya Keiko Ohashi. In I. N. Suparwa \& S. Damayanti (Eds.), Tiga Paradigma Analisis Wacana 
Kritis dan Penerapannya (pp. 93117). Swasta Nulus.

Hafstad, G. S., Haavind, H., \& Jensen, T. K. (2012). Parenting After a Natural Disaster: A Qualitative Study of Norwegian Families Surviving the 2004 Tsunami in Southeast Asia. Journal of child and family studies, 21(2), 293-302. https://doi.org/10.1007/s10826011-9474-z.

Kenichiro, K. (2012). Ehon to Kodomo no Ningen Keiseiron: Tasha to no Kaigō no Fukanōsei to Kanōsei. Annals of Educational Studies, 17, 89-100. doi/10.18910/8626.

Kukihara, H., Yamawaki, N., Uchiyama, K., Arai, S., \& Horikawa, E. (2014). Trauma, Depression, and Resilience of Earthquake/Tsunami/Nuclear Disaster Survivors of Hirono, Fukushima, Japan. Psychiatry and Clinical Neurosciences, 68 (7), 524-533. doi: 10.1111/pcn.12159.

Levine, P. dan Kline, M. (2010). Trauma Through a Child's Eyes: Awakening the Ordinary Miracle of Healing - Infancy Through Adolescence. North Atlantic Books.

Masten, A. S. (2014). Ordinary Magic: Resilience in Development. Guilford Press.

Minderop, A. (2018). Psikologi Sastra: Karya Sastra, Metode, Teori, dan Contoh Kasus. Yayasan Pustaka Obor Indonesia.

Mitsuoka, M. (2013). Minna de Utau be! (O.Yoshiko, Illus.). Gakken Education.

Miyagiken Kodomo Sōgō Sentā. (2016). Higashinihon Daishinsai ni okeru Kodomo no Kokoro no Kea ni kansuru Hōkoku. Miyagi
Prefectural Government. https://www.pref.miyagi.jp/docume nts/15133/356072_1.pdf.

Mohammadinia, L., Ardalan, A., Khorasani-Zavareh, D., Ebadi, A., Malekafzali, H., \& Fazel, M. (2018). Domains and Indicators of Resilient Children in Natural Disasters: A Systematic Literature Review. International journal of preventive medicine, 9, 54. https://doi.org/10.4103/ijpvm.IJPV M_1_18.

Nakamura, M. (2017). Higashinihon Daishinsai Ato no Tsuitō ya Fukkō to Ongaku no Kakawari ni Kansuru Gakusaiteki Kenkyū. KAKEN Project. https://kaken.nii.ac.jp/ja/grant/KAK ENHI-PROJECT-25580023/.

Reivich, K. \& Shatte, A. (2003). The Resilience Factor: 7 Keys to Finding Your Inner Strength and Overcome Life's Hurdles. Broadway Books.

Sinarsih, A., Handani, Y., \& Tjong, C. (2015). Dampak Psikologis Tokoh Pria dan Wanita dalam Film Tangshan Da Dizhen. Jurnal Lingua Cultura, 9(2), 120 - 126. https://doi.org/10.21512/lc.v9i2.83 0 .

Suparmi \& Sumijati, S. (2021). Pelatihan Empati dan Perilaku Prososial pada Anak Usia Sekolah Dasar. PSIKODIMENSIA Kajian Ilmiah Psikologi, 20(1), 46-58. 10.24167/psidim.v20i1.2879. 